\title{
Cerrena unicolor (BULL.) MURR (BASIDIOMYCOTA) AISLADO DE MICANGIO DE Tremex fuscicornis FABR. (HYMENOPTERO SIRICIDAE) ASOCIADO A DECAIMIENTO Y PUDRICION DEL ALAMO (Populus sp.) EN CHILE
}

(Cerrena unicolor(Bull.)Murr.(Basidiomycota) isolated from mycangia of Tremex fuscicornis Fabr. (Hymenoptera Siricidae) associated to poplar decline

(Populus sp.) in Chile)

\section{Ma. Antonieta Palma C. ${ }^{1}$, Eduardo Valenzuela², Patricio Parra ${ }^{3}$, Mónica Gutierrez ${ }^{4}$, Luis Torelli Silva ${ }^{1 .}$}

1. Laboratorio Agrícola SAG Valparaíso. E-mail: laboratorio.valparaiso@sag.gob.cl. 2. Instituto de Microbiología Universidad Austral de Chile.E-mail: evalenzu@uach.cl.

3. Instituto Forestal de Chile. E-mail: pparra@infor.cl 4. Laboratorio Agrícola SAG Osorno. E-mail: monica.gutierrez@sag.gob.cl

Palabras clave: Tremex fuscicornis, Cerrena unicolor, Populus, Chile. Key words: Tremex fuscicornis, Cerrena unicolor, Populus, Chile.

\section{RESUMEN}

Entre septiembre a diciembre del 2004 el Instituto Forestal y el Servicio Agrícola y Ganadero, en investigaciones conjuntas de estrategias de control biológico para Tremex fuscicornis Fabr. (Hym. Siricidae), se profundizó en el conocimiento de la asociación simbiótica que presenta esta avispa xilófaga con un hongo. T. fuscicornis, es una avispa taladradora del álamo que presenta en sus glándulas micangiales el micelio y esporas de un hongo asociado, el cual inyectado al árbol en el momento de la oviposición, causa su posterior decaimiento y biodegradación. Desde hembras adultas se obtuvieron los micangios que contenían micelio $y$ artrosporas del hongo, estos fueron macerados $y$ posteriormente sembrados en agar papa dextrosa, desarrollándose colonias fúngicas que formaron artrosporas. El micelio de estas colonias fue inoculado en varios tipos de sustratos vegetales esterillizados, en especial en trozas de álamo, donde se desarrollaron basidiocarpos, los que taxonómicamente correspondieron a Cerrena unicolor (Bull.) Murr., primer reporte para Chile de este basidiomicete.

\section{ABSTRACT}

Since september to december 2004, Instituto Forestal and Servicio Agrícola y Ganadero, while investigating together the strategies for the biological control of Tremex fuscicornis Fabr. (Hym.Siricidae), acquired thorough knowledge about the symbiotic association existing between this xylophagus wasp with a fungus. T. fuscicornis is a horntail wasp attacking poplar trees and which has in its mycangial glands the mycelium and spores of an associated fungus that once injected in the tree at the oviposition stage, causes its further decay and rottenness.

Mycangia containing mycelium and arthrospores of this fungi were obtained from adult females. They were macerated and then cultivated in potato dextrose agar (PDA) what resulted in fungal colonies that further formed arthrospores. The mycelium of these colonies was inoculated into different kinds of sterilized vegetal substrates, mainly in pieces of poplar trees, where basidiocarpes were developed, taxonomically corresponding to Cerrena unicolor (Bull.) Murr., this being the first report on this basidiomycete in Chile 


\section{INTRODUCCION}

Los álamos (Populus sp.) en Chile son considerados una especie forestal de importancia económica junto a los Pinos y Eucaliptus (FAO, 1980). Desde el punto de vista patológico, el principal síntoma de los bosques estudiados, es la pudrición de la madera, producto de su biodegra-dación, ocasionada por hongos lignívoros (Donoso, 1968 citado por Gonzalez y Opazo, 2002).

El Servicio Agrícola y Ganadero (SAG), detectó el año 2000 la introducción en algunas Comunas de Chile de la avispa taladradora de la madera de latifoliadas Tremex fuscicornis (Hym. Siricidae) constituyéndose por Resolución Nº 3303 del 26/12/2000 como «Plaga de Control Obligatorio» para las Regiones Metropolitana, V y VI del País ( SAG, 2000). Basados en estos antecedentes se hizo necesario profundizar el conocimiento de la biología de esta plaga con orientación a futuras estrategias de control biológico tendientes a reducir el avance y controlar su población en áreas infestadas de Chile.

Los insectos de la Familia Siricidae viven en asociación simbiótica con un hongo basidiomicete el cual es capaz de degradar la lignina, concentrando en su micelio elementos nutritivos poco abundantes en la madera como nitrógeno, fósforo y potasio, dejándolos disponibles para el insecto (Kirk \& Fenn, 1982). El hongo sirve de alimento a las larvas y se propaga mediante esporas y micelio que se almacena en dos sacos o micangios (glándulas adosadas al sistema reproductor) situados en la cavidad abdominal de la hembra y que desembocan en la base del ovipositor del insecto (Franke-Grossmann citado por Dajoz, 2001). Las esporas del hongo son expulsadas con los huevos al momento de la ovipostura; sumando además un mucus fitotóxico producido por el insecto (fenoles, proteasas y polisacáridos) que en conjunto van produciendo el decaimiento de los árboles colonizados por Tremex (Chiarello et al.,1999). Esta lesión avanza con compromiso del duramen, produciendo una pudrición blanca de la madera «white rot» causada por el basidiomicete que produce una cantidad importante de enzimas lignolíticas degradadoras de este substrato (Belova \& Gavrilova, 2000; Dajoz, 2001). En la pudrición blanca la lignina es atacada y lo que queda de paredes celulares toma una consistencia fibrosa y de color blanco, debido a la lisis de las células del xilema, causadas por las fenolasas que degradan la lignina por oxidación (Kirk \& Fenn citados por Dajoz, 2001). También en las larvas hembras hay micangios, así en la última muda larvaria el tegumento de la pupa es contaminado por las esporas del hongo lo que asegura su transmisión a la hembra adulta (Franke-Grossmann citado por Dajoz, 2001). Según Tabata y Abe (1995) y Greinfenhagen \& Hopkin (1998) este hongo participa en la degradación de algunos constituyentes de la madera de árboles en pie.

La presente investigación corresponde al seguimiento realizado por INFOR-SAG a la plaga de control obligatorio de T. fuscicornis, (S A G, 2000) que no sólo causa daño por las perforaciones emergentes de aproximadamente $6 \mathrm{~mm}$ en árboles adultos (Parra et al, 2005), sino también por el decaimiento y biodeterioro causado por el hongo.

La presente investigación tuvo como objetivo identificar taxonómicamente el hongo simbionte presente en las glándulas micangiales de esta avispa.

\section{MATERIALES Y METODOS}

En la primera etapa de investigación (Septiembre a Diciembre del 2004), se procedió a realizar una prospección tomando muestras de 100 ejemplares de la avispa Tremex fuscicornis, durante la temporada de vuelo del insecto en la Comuna de Los Andes, Provincia de Aconcagua, V Región de Chile (Instituto Forestal, INFOR). Los ejemplares fueron enviados al Laboratorio de Fitopatología del SAG Valparaíso. Inicialmente los insectos fueron identificados por el Entomólogo del Laboratorio, procediéndose a extraer los micangios (dos), usando la siguiente metodología:

Hembras adultas de T. fuscicornis se depositaron en placas Petri que contenían agua destilada estéril. Luego se extrajo la porción medio abdominal, eliminando la grasa presente además de patas y cabeza del insecto. A continuación se ubicaron los ovarios y de su parte inferior se extrajeron 2 glándulas de color café canela que contenían en su interior las estructuras fúngicas a estudiar, que le confieren dicha coloración. Se recolectaron las glándulas en vidrio reloj y se almacenaron en tubos con agua destilada estéril a $4^{\circ} \mathrm{C}$ en refrigeración (no más de 48 hrs), hasta ser sembrados en medio de cultivo agar papa dextrosa (APD). Una vez obtenidos los micangios, se maceraron (el tejido con micelio y artrosporas) y con ayuda de un asa el macerado fue sembrado en 3 placas que contenían APD, cada placa fue identificada para cada individuo tratado. Sembradas las placas fueron incubadas a $23^{\circ} \mathrm{C}$ durante 8 días en oscuridad. Al término del proceso se realizó el trabajo taxonómico para caracterizar las colonias del hongo aisladas en su estado de desarrollo de colonia (micelial vegetativa). Se seleccionaron, al azar 20 cepas las cuales fueron utilizadas en las inoculaciones posteriores.

En una segunda etapa de la investigación se procedió a propagar in vitro las cepas aisladas del hongo en 3 sustratos vegetales ricos en celulosa y lignina, estos correspondieron a: astillas y trozas de álamo (Populus sp.) y paja de trigo (Triticum aestivum). Los sustratos se 
inocularon con discos (obtenidos con un sacabocados) de $1 \mathrm{~cm}$ de diámetro de agar con micelio de la cepa fúngica a ensayar, para ello los discos de agar con micelio se depositaron sobre el sustrato y se determinó la tasa de crecimiento del micelio. A continuación se detalla la metodología aplicada para cada uno de los sustratos evaluados:

a.- Astillas de álamo de $10 \mathrm{~cm}$ de largo por $1 \mathrm{~cm}$ de diámetro previamente esterilizadas en autoclave, $\left(121^{\circ} \mathrm{C} 15 \mathrm{lb}\right.$ de presión por 15 minutos), depositadas en un matraz de $1000 \mathrm{~mL}$, que contenía en su base una capa de $1 \mathrm{~cm}$ de APD, sobre estas astillas se inoculó el micelio. Sembrados los matraces se incubaron en oscuridad a $23^{\circ}$ C por 20 días. También utilizando la metodología antes descrita y en las mismas condiciones de cultivo, se realizaron ensayos en aserrín de álamo.

b.- Paja de trigo dos veces esterilizada en autoclave durante 10 minutos ( $15 \mathrm{lb}$ de presión, $120^{\circ} \mathrm{C}$ ), se inoculó con el hongo y luego se depositó en bolsas de polietileno negras incubándose en oscuridad a $23^{\circ} \mathrm{C}$ por 20 días.

c.- Trozas de álamo de 20 o más $\mathrm{cm}$ de longitud por $10 \mathrm{~cm}$ de diámetro esterilizadas dos veces en autoclave por 1 hora (15 lb de presión, $120^{\circ} \mathrm{C}$ ). Previo a la esterilización las trozas se perforaron mecánicamente en 5 puntos simulando el diámetro del orificio causado por el insecto (hasta $6 \mathrm{~mm}$ de diámetro). Luego de la inoculación con la cepa fúngica las trozas se cubrieron con bolsas plásticas transparente de polietileno y fueron incubadas a $23^{\circ} \mathrm{C}$ en oscuridad por 20 días.

En una última etapa, obtenidos los basidiocarpos desde el sustrato inoculado artificialmente, se enviaron al Laboratorio de Microbiología de la Universidad Austral de Chile para su identificación taxonómica hasta el rango de especie, determinación que realizó uno de los coautores del presente trabajo.

\section{RESULTADOS Y DISCUSION}

Al realizar la extracción de los micangios de los ejemplares de hembras de T. fuscicornis (Fig. 1.1) captadas en las muestras de la comuna de Los Andes V Región, se observó que estos sacos micangiales (Fig. 1.2) presentaban forma redondeada con pared membranosa de color café claro, al ser diferenciados microscópicamente en su interior se observó un micelio de color canela, formado por hifas anchas y artrosporas de pared gruesa. Estos micangios se distinguen de los ovarios del insecto que son estructuras en forma de pera blanquecinas a traslúcidas y en ocasiones contienen huevos en su interior. Tabata y Abe (1995), también han reportado la ocurrencia de artrosporas dentro del micangio.

En lo que respecta a los cultivos fúngicos (Fig. 1.3) obtenidos desde la siembra de tejido micangial en APD, se evidenció el desarrollo de colonias aisladas de color blanco conformadas por un micelio blanquecino ralo a levemente aterciopelado. Al avanzar el crecimiento del cultivo, éste se torno de color blanco cremoso con leve tonalidad amarilla, conservado este color al reverso de la colonia. Aproximadamente a los 20 días se observaron hifas vegetativas de $1 \mu \mathrm{m}$ de ancho, de paredes más o menos delgadas sin septos, posteriormente (30 días) se desarrollaron hifas más gruesas de 2-3,5 $\mu \mathrm{m}$ de ancho probablemente generativas, que en un escaso porcentaje (2\%) de las cepas revisadas se evidenciaron septos con hebilla (clamp-conection). Esta situación probablemente se debió al alto grado de incompatibilidad al ser cepas del mismo origen. En los cultivos de 14-20 días bajo régimen de oscuridad a $23^{\circ} \mathrm{C}$, se observaron hifas formativas «parentales» que producían artrosporas unicelulares, semejando fragmentos de hifas que dependiendo del micelio podrían ser uni, bi o multinucleadas, además con el envejecimiento del cultivo se observaron hifas terminales anchas. Las características macromicroscópicas antes señaladas y de acuerdo a los esquemas de clasificación taxonómica de Nobles (1965), permitieron determinar que los cultivos obtenidos correspondieron a un hongo de los Aphyllophorales (actualmente Orden Polyporales) del género Cerrena.

Durante la segunda etapa, una vez identificadas las cepas «madres» se observó en todos los aislados un crecimiento uniforme, que en promedio alcanzó los $3 \mathrm{~cm}$ de diámetro a los 7 días de incubación. En esta etapa de ensayo se obtuvieron aproximadamente 100 cepas de los distintos envíos realizados por INFOR, de ellas se eligieron 20 al azar que fueron utilizadas en la etapa siguiente de inoculación de los sustratos.

Al relacionar los sustratos inoculados artificialmente y su respuesta adaptativa al inóculo, su tasa de crecimiento (a los 10, 20, y 30 días) y su posible contaminación con otros microorganismos, se determinó que el mejor sustrato evaluado fueron las trozas de álamo y el peor el aserrín, por el lento crecimiento fúngico, el cual no continúo a partir de los 20 días de incubación. Por su parte en la paja de trigo, el principal problema detectado fue la contaminación, aunque el crecimiento fúngico fue aceptable, similar al determinado en las trozas de álamo. En esta etapa el sustrato óptimo seleccionado (las trozas de álamo), luego de ser inoculado con el micelio de las cepas sobre los orificios realizados mecánicamente, comenzó a tomar una coloración blanco-amarillenta, posteriormente una tonalidad café tabaco y en el transcurso del período de incubación de 20 a 40 días se evidenció la aparición de algunos primordios de diferenciación fúngica, sin embargo, en una gran mayoría de los ensayos se observó un cese en su desarrollo. Esto podría deberse a 

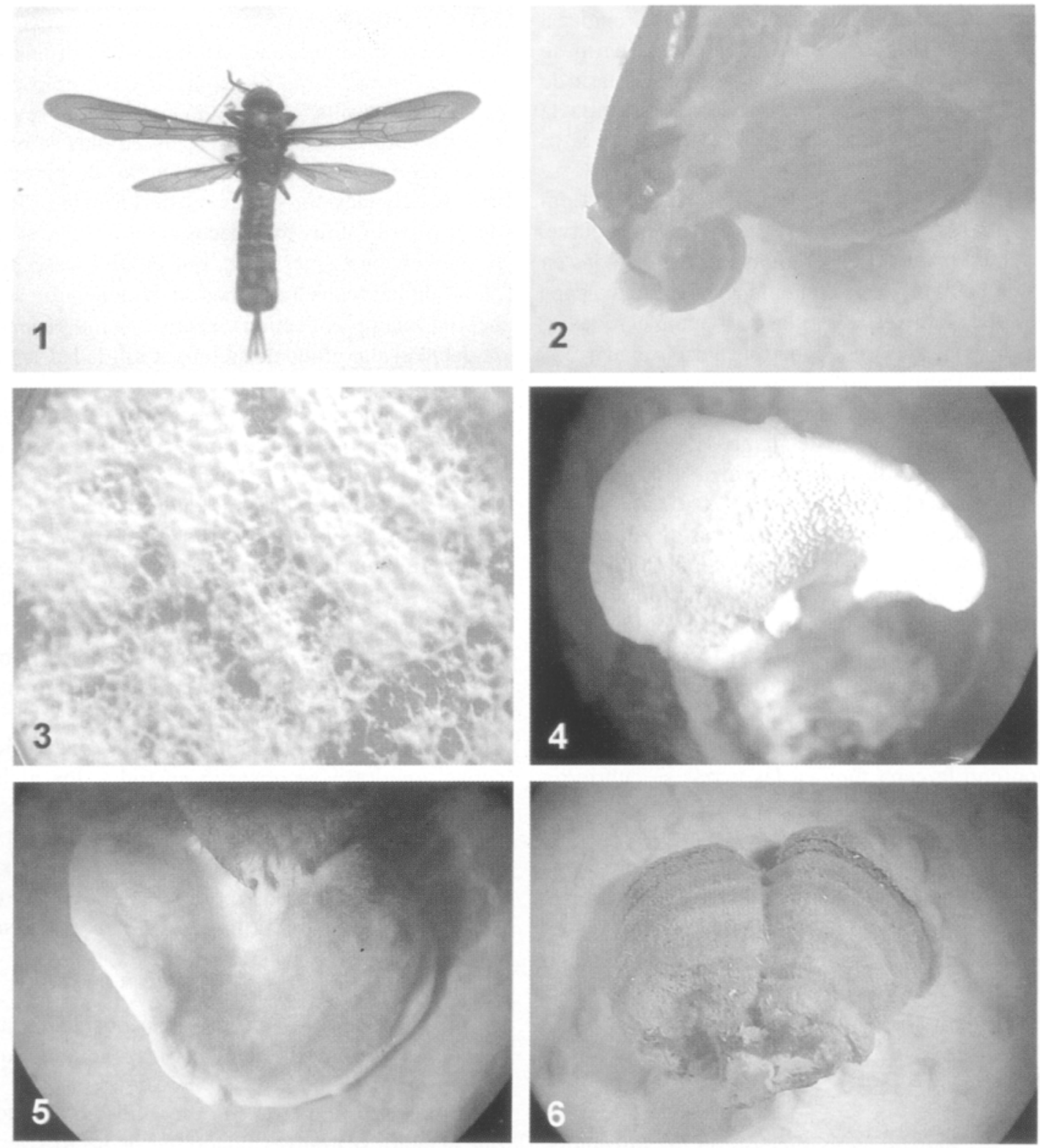

Figura 1. - 1. Hembra adulta de T. fuscicornis. 2. Micangios en par de 1,5 a $2 \mathrm{~mm}$ de largo. 3. Miceíio ue c. unicoior en medio APD. 4. C. unicolor en formación faz porosa. 5. C.unicolor en formación faz pubescente. 6. Basidiocarpo de C. unicolor.

que muchos Aphyllophorales (según la denominación de Alexopoulos, 1996), aún cuando exhiben el ciclo de vida típico de los Basidiomycetes, pueden presentar un proceso de dicariotización regulado por un sistema de incompatibilidad bifactorial (factor A y B). Al respecto, Stenlid \& Rayner (1991) y Nobles (1965), señalan que una alta proporción de hongos causantes de pudrición blanca de la madera, especialmente de la familia Polyporaceae, son conocidos por tener un sistema de apareo unifactorial o bipolar, esto significa que micelios con genes de apareo semejantes no son compatibles, o sea, presentan incompatibilidad homogénica. La incompatibilidad homogénica de los Aphyllophorales heterotálicos, afecta la fusión de micelios homocarióticos, como habría ocurrido en Cerrena, no permitiendo en un elevado porcentaje de las cepas ensayadas, el cruzamiento entre hifas compatibles para formar el micelio secundario heterocariótico que da origen a los basidiocarpos. Al respecto Tabata \& Abe (1995), en un estudio realizado en Japón, señalan la existencia de cepas heterotálicas y bipolares de Cerrena en Tremex. 
En el presente estudio se asume que las cepas que originaron basidiocarpos, corresponden a aquellas que presentan compatibilidad. Estas cepas ( Figuras 1.4 y 1.5), desarrollaron primordios de aproximadamente $5 \mathrm{~mm}$ de diámetro, casi sésiles, que comenzaron a crecer lentamente hasta alcanzar un tamaño de $0,7 \mathrm{~mm}$ a $19 \mathrm{~mm}$ de diámetro a los 114 días de incubación del sustrato. Se determinó que taxonómicamente los basidiocarpos corresponden a Cerrena unicolor (Bull.) Murrill. (Fig. 1.6), perteneciente a la Clase Basidiomycetes, Orden Polyporales y Familia Polyporaceae. Los basidiocarpos de $\boldsymbol{C}$. unicolor como se muestra en la figura 1.5, presentan una forma de ostra irregular, son sésiles, su cara inferior tiene una tonalidad blanquecina a gris y su cara superior es de color café canela, con cierta pubescencia y algunos pelos hirsutos erectos de color café más oscuros. Los poros en su cara inferior, están agrupados formando una especie de laberinto de aspecto cerebriforme. El pseudotejido es carnoso y de color crema, las características antes señaladas concuerdan con lo indicado por Breitenbach \& Kränzlin (1986) para C. unicolor.

En Chile, el hábitat de $\boldsymbol{C}$. unicolor sería en la madera de árboles en pie, donde causaría una pudrición blanca (white-rot, sapwoodrot), aunque, en las especies arbóreas de la comuna de Los Andes no se han observado cancros, sino más bien decaimiento y degradación severa de la madera, especialmente en aquellos árboles infectados por T. fuscicornis. Sin embargo, Greifenhagen \& Hopkin (1998), señalan que $\boldsymbol{C}$. unicolor en condiciones climáticas extremas resulta ser más agresivo, causando decaimiento y lesiones cancrosas, llegando incluso a provocar la muerte de los árboles.

\section{CONCLUSIONES}

El presente estudio se considera como el primer reporte de Cerrena unicolor (Bull.) Murr. para Chile, un hongo simbionte presente en los micangios de Tremex fuscicornis Fabr., desde la V Región. Su aislamiento y cultivo in vitro desde esta avispa taladradora del álamo permitió la obtención de sus basidiocarpos. El decaimiento de este árbol afectado por el insecto, se atribuye a la capacidad degradadora de la madera por el hongo, lo que conduce finalmente a la muerte del tejido del duramen de estos árboles.

\section{REFERENCIAS}

Alexopoulus, C.; Mims, C. \& Blackwell, M. (1996). Introductory Mycology. Edit. John Wiley, NY. USA.

Belova, N. \& Gavrilova, V. (2000). Destroying Basidiomycetes as producer of lignolitia enzymes. Kamarov Botanical Institute RAS, 197376 St. Petersburg, Russia. pp. 29-31
Breitenbach, J. \& Kränzlin, F. (1986). Fungi switerland. Verlag Mycologia, CH-600 Lucerne, Switzerland.

Chiarello, S.; Tadeu, E. \& Castellano, C., (1999). Publicación: Aspectos biológicos e recomendacoes para criacao massal e uso do nematoide Deladenus siricidicola no controle biologico de Sirex noctilio Hym. Siricidae. Embrapa Brasil.

Dajoz, R. (2001). Entomología Forestal, Los insectos y el bosque. Papel y diversidad de los insectos en el medio forestal. Ed. Mundi Prensa España. Cap. 14.pp. 349-373

Francke-Grossmann, H. (1967). Ectosymbiosis in wood inhabiting insects. In: M. Henry (ed.) Simbiosis, Vol. 2. Academic Press, New York. pp.141-205

Gonzalez, G. \& Opazo, A. (2002). Enfermedades fungosas y otras. En: Baldini, A. (ed). Agentes de daño en el bosque nativo, Editorial Universitaria, Santiago-Chile. pp:89-199

Greinfenhagen, S. \& Hopkin, A. (1998). Forest Research. Decay, Stain and Wood-boring beetles. Eastern Ontario Model Forest (EOMF), Kemptville, ON ( 613 -258 - 8241), 4 p. (http:// insfratt.eomf.on.ca/pdfs/pub12.pdf)

Nobles, M. (1965). Identification of cultures of wood-inhabiting. Hymenomycetes. Can. J. Bot. 43:1097-1139

Kirk, T. \& Fenn, P. (1982). Formation and action of the lignotylic system in Basidiomycetes. In: JC. Frankland; J.N. Hedger y M.J. Swift, 1982; Recomposer Basidiomycetes. Their biology and ecology. Cambridge, University Press, pp. 67-90

Organización de las Naciones Unidas para la Agricultura y la Alimentación (FAO). (1980). Los Álamos y los Sauces en la producción de madera y la utilización de las tierras.Colección FAO: Montes, Roma.

Parra, P.; González, M.; Soto, D. \& Salinas, A. (2005). La avispa taladradora de la madera Tremex fuscicornis (Fabr.). Informativo Sanitario Forestal $N^{\circ} 4$. Instituto Forestal.

Servicio Agrícola y Ganadero (SAG, 2000). Chile. http:// www.sag.gob.cl/contenedortmp/Normas_de_Control_Oficial_de_ Plagas/tremex.html

Stenlid, J. \& Rayner, A. (1991). Patterns of nuclear migration and heterokaryosis in pairings between sibling latifoliae homokaryons of Heterobasidion annosum. Mycological Research 95:1275-1283

Tabata, M. \& Abe, Y. (1995). Cerrena unicolor isolated from mycangia of a horntail, Tremex longicollis, in kochi Prefecture, Japan Mycoscience 36:447-450

Talbot, P. (1997). The Sirex-Amylostereum Pinus Association Annual. Review Phytopathol. 15:41-54 